\title{
Social interactions of assertive individuals
}

\begin{abstract}
Assertive behavior is a constructive alternative to manipulation and aggression, so it is important to study the issues related to assertiveness. In theory, it is very important that assertiveness includes the connection between values, attitudes and behavior. This manifests itself in practically important aspects of the social interaction of assertive personalities with others. The tasks of this pilot study are:
\end{abstract}

1. To identify possible links of assertiveness of the individual with the choice of strategy of behavior in the conflict, with communicative self-control, with the degree of her satisfaction with work, marriage and life in general.

2. To detect mental differences when comparing the results obtained with similar results of foreign researchers. A total of 421 subjects participated in the study: 228 men and 193 women aged 21-77 years.

The study reveals the relationship of assertiveness of the individual with the choice of her strategies of behavior in the conflict, with her communicative self-control, satisfaction with work, life in general, and marriage. Most of these links have a different character than those found in foreign studies. However, the results obtained for men and for women are significantly different. In the strategies of behavior in conflict common for men and women are: a positive relationship of assertiveness with such a strategy of behavior in the conflict as rivalry, a negative relationship with the adaptation strategy and a lack of connection with the strategy of cooperation. The average indicator of the choice of the strategy of rivalry in men is statistically significantly higher than that of women, and the average "female" indicators of the choice of the strategy of cooperation and adaptation surpass those in men.

Keywords: assertiveness, personality, social interaction, strategies for behavior in conflict, communicative self-control, satisfaction with work, life and marriage, men are women
Volume 9 Issue 6 - 2018

\author{
Victor P Sheinov \\ Department of Psychology, Republican Institute of higher \\ school, Belarus
}

\begin{abstract}
Correspondence: Victor P Sheinov, Republican Institute of Higher School,22000I, Moskovskaya street, Minsk, Belarus, Email sheinovl@mail.ru
\end{abstract}

Received: January 25, 2018 | Published: December 19, 2018

\section{Introduction}

"Assertiveness is the ability of a person to defend his rights confidently and with dignity, while not disregarding the rights of others. Assertive is a direct, open behavior, not intended to cause harm to other people ". ${ }^{1}$ This definition reflects the main thing that unites the views of the authors who made a significant contribution to the study of assertiveness. ${ }^{2}$ The person is assertive, if she has this ability. Assertive behavior is a constructive alternative to manipulation and aggression, ${ }^{1-4}$ which makes it relevant to study the whole complex of issues related to assertiveness. Reflecting the relevance is a large number of works (while mostly foreign), published, including, and in recent years. A small part of them (related to the subject of the article) is presented in the literature list. ${ }^{1-5,6-18}$ In practical terms, the study of assertiveness is relevant, in particular, because the "portrait" of the assertive personality, represented in the works mentioned, includes many positive social and psychological qualities. Therefore, the relevant knowledge of them will be useful in psychological counseling, psychotherapeutic work and, in particular, will help to substantiate and complete the concrete content of assertiveness trainings, which are currently performed in our foreign models and do not sufficiently take into account the mental characteristics of the trainees. In theory, it is very important that assertiveness includes the connection between values, attitudes and behavior. ${ }^{7}$ This should manifest itself (and, as numerous studies show, it does manifest itself ${ }^{2-20,5-21,6-18}$ in important aspects of the social interaction of assertive personalities with others.

According to a study by Tanska R \& Robbins $\mathrm{P},{ }^{16}$ a person with high scores on the scale of assertiveness is quite sociable, analyzes his problems, shares them, actively acts. Unlike people with a low level of assertiveness, the assertive person is less inclined to irritability, solitude or passive patience of inconveniences. Assertiveness is in a statistically significant positive relationship with such a mechanism of psychological adaptation to stress, as a solution to the problem. In the work of M. Becker et al. it was shown that the assertiveness of the individual is a serious predictor of his ability to have his own point of view, to succeed in interpersonal relations. Assertive behavior gives an advantage in critical situations, conflicts that entail serious consequences; analysis of cases when assistance is needed, has confirmed the advantage of assertive behavior for satisfying vital needs. ${ }^{15}$ Conduct in conflict. Important information, both in the theoretical and practical aspects of social interactions assertive personality gives her choice of strategies for behavior in the conflict. Publications of Russian psychologists on this topic could not be found, so let's look at foreign sources. Ergenel A et al. ${ }^{22}$ revealed a positive correlation between assertiveness and the style of rivalry when employees are in conflict with peers equal in their rank. This result corresponds to the assertion that assertive subjects act in such a way as to obtain in the conflict situation "a large fraction of the pie". ${ }^{10}$ However, there are no significant links between assertiveness and such strategies as compromising, obliging and integrating in conflict with both superiors and peers.

According to the work of Weiss $\mathrm{S},{ }^{18}$ individuals with low assertiveness can behave in a conflict situation, proceeding from an attitude to care more about the feelings and well-being of others, rather 
than about their feelings and well-being. The behavior in the conflict is related to how his participant suffers the stress caused by this conflict. It is established ${ }^{16}$ that the assertive personality tends to such a mechanism of psychological adaptation to stress, as a solution to the problem. With an increase in the level of assertive skills, the severity of conflicts and stresses decreases. ${ }^{5}$ Satisfaction with work. The nature of human social interactions is affected by the degree of satisfaction or dissatisfaction with the result of these interactions. Satisfaction with work generates a positive attitude towards it, a manifestation of initiative, and dissatisfaction - a negative attitude towards work, passivity and / or conflicts, and even a desire to change the place of work. Therefore, it is natural to be interested in the question whether satisfaction with work is associated with the assertiveness of the individual. There are several works by foreign authors on this topic.

Thus, Rowntree $\mathrm{J}^{15}$ found a statistically highly significant positive relationship between the indicators of assertiveness and job satisfaction. John Lownesbury et al. ${ }^{5}$ reviewed the characteristics of 1,059 IT professionals associated with their job satisfaction and career. The following signs were statistically significantly associated with job satisfaction and career: assertiveness, emotional stability, extraversion, openness, teamwork planning, customer service orientation, optimism. At the same time, the correlation value of assertiveness with career satisfaction was generally higher than the corresponding correlations with job satisfaction. In a study by E. Ryan and colleagues, ${ }^{15}$ it is shown that both young and elderly women of assertive behavior are more competent, and they are more likely to achieve their goals.

Butt A \& Zahid $Z^{23}$ showed that assertive skills reduce burn-out at work, which contributes to satisfaction with it. With the increase in the level of assertive skills, coherence and trust increase, the severity of conflicts and stresses decreases, which also leads to a reduction in burnout. Satisfaction with life and marriage. The degree of satisfaction or dissatisfaction with these interactions influences the nature of the social interactions of the person with others and, in particular, of the relations in the family. John Lownsbury ${ }^{5}$ found that assertiveness is positively and statistically highly significant $(\mathrm{R}=0.27, \mathrm{p}<0.001)$ correlated with life satisfaction. At the same time, female students showed higher results of assertiveness than male students. This study did not reveal any significant differences in life satisfaction, depending on gender.

A significant positive relationship between assertiveness and life satisfaction was found in other works. ${ }^{15}$ Those who are married are generally more assertive than single people. ${ }^{14}$ Mitrofan L \& Dumitrache $\mathrm{S}^{7}$ showed that assertive partners are more satisfied with their relations. Among the skills of husbands important for the satisfaction of wives by marriage, they are called assertiveness and empathy of husbands. ${ }^{17}$ In social interactions of a person, his ability (or inability) to exercise control over his behavior can be manifested, and, thus, influence the impression that is formed about him by others. This ability is denoted by the term communicative self-control. It affects the nature of the interaction of the individual with others and is therefore interesting for study. Unfortunately, we were not able to find works devoted to the question of identifying the presence or absence of communicative self-control in assertive personalities. Comparison of the results obtained in the Russian-speaking society, with the results of foreign research, often reveals mental differences. For example, it is established ${ }^{19}$ that assertiveness does not depend on the age of an adult, while in foreign works such dependence is traced. A positive relationship between assertiveness and internality has been revealed, both in men and women, ${ }^{20}$ while in the English-speaking society it occurs only in men. The facts established $i^{3}$ were not found in foreign studies: the significant influence of gender on the presence and level of assertiveness relations with a number of psychological and sociopsychological qualities, the positive relationship of assertiveness with "constructive aggressiveness" and negative - with dependent behavior.

Therefore, the results of foreign research can be used in practical work in our society only after they have been checked by domestic research, which was one of the objectives of the study. The aim of the study was to determine the nature of the social interactions of the assertive personality. To achieve this goal, the following tasks were set:

1. To identify in the Russian-language society possible links of assertiveness of the individual with strategies of behavior in the conflict, communicative self-control, with a degree of satisfaction with work, marriage and life in general;

2. To find mental differences in comparing the results obtained with similar results of foreign researchers.

\section{Methodology}

\section{Participants in the study}

A total of 421 subjects participated in the study: 228 men aged 22 to 77 years $(M=41)$ and 193 women aged 21-75 $(M=39)$. Subjects represented a wide range of professions, service statuses and regions of residence:

1. 169 students of advanced training courses at the Republican Institute of Higher Education (RIVSCH, Minsk) - 94 teachers of higher and secondary special educational institutions of Belarus and 75 managers and specialists of enterprises of various ownership forms.

2. 93 students of the Academy of Postgraduate Education (APO, Minsk): directors of secondary schools and educational and pedagogical complexes (kindergarten + school) -19 people; heads and specialists of education management bodies -29 people, teachers and educators of educational institutions -29 people, psychologists -25 people.

3. 78 teachers of Minsk secondary schools and gymnasiums.

4. 31 workers of the Ministry of Emergency Situations of the city of Gomel.

5. 30 teachers of the Brest State University. A.S. Pushkin. Procedure of the study. Communication with the test subjects and their collective testing took place in the process of conducting training sessions with them (psychodiagnostics is included in the curriculum). All subjects were given a set of 6 tests and an answer sheet with the personal cipher of the subject written on it for feedback to the researcher. Before the testing, the test subjects were instructed to motivate participants to take a serious attitude to the survey. It was suggested anonymously to answer test questions in order to "learn about some of their qualities that are extremely important for success in professional work, in the family and in relations with others." For the rejection of substandard answers in each set of tests, there was a "scale of lies". If they doubted the reliability of the answers, they were deleted, and the subject was asked to retake the test. But there were few such cases, the subjects showed interest in testing.

\section{Methodical tools}

To assess assertiveness, the author's technique was applied, the 
reliability and validity of which was proved earlier. ${ }^{3}$ The methodology includes a questionnaire of 26 questions aimed at finding out how a person behaves towards others, friends, close people and how he reacts in certain situations. The subject specifies the point of the digital scale, his answers are summed up. The total score correlates with the boundaries of the "assessiveness range": the result from 66 to 77 (inclusive) points, characterizes the assertive personality. If the total score is less than 66 or more than 77 , then the subject is not assassative: in the first case he is characterized by uncertain behavior and inability to uphold his rights; secondly, by violating the rights of others and aggressive behavior. Using this procedure, the assertive subjects were selected in the study. ${ }^{3}$ To describe the types of people's behavior in conflicts and their quantitative assessment, K. Thomas's test was used (adapted by NV Grishina), ${ }^{23}$ which reveals the behavior strategies of the subject in the conflict. The test implements a twodimensional model of $\mathrm{K}$. Thomas dealing with conflict resolution, which reveals the relationship between a person's taking into account the interests of other people involved in the situation and an emphasis on his own interests. In accordance with these two trends, the model identifies five ways to resolve conflicts:

1. Competition (competition) - the desire to achieve their interests at the expense of another;

2. Adaptation - sacrifice of one's own interests for the sake of another;

3. Compromise - an agreement based on mutual concessions, the proposal of a variant that removes the contradiction that has arisen;

4. Avoidance - lack of aspirations and to take into account the interests of other participants in the conflict, and to achieve their own goals;

5. Cooperation - the participant of the situation strives to fully satisfy the interests of both parties.

To measure communicative self-control - a person's ability to exercise control over his behavior and thereby influence the impression of others around him, the Self Monitoring Scale was used, which is a personal questionnaire designed by Mark Snyder in 1974. The scale makes it possible to distinguish between people who are good at managing the impression produced ("well-governed by oneself") and people whose behavior is determined by internal attitudes rather than by the desire to impress ("badly governing oneself"). The version of the questionnaire in the adaptation of Amyaga $\mathrm{NV}^{24}$ is used in the work. Satisfaction with work was assessed in subjects using the technique "Integral Satisfaction with Labor," developed by N.P. Fetiskin and co-authors. ${ }^{25}$ In this methodology, an integrative indicator that reflects the well-being / unhappiness of the individual in the work collective includes self-assessments of interest in the work performed, satisfaction with the relationships with employees and management, the level of claims in the professional activity, satisfaction with the conditions and organization of work, etc. This methodology allows us to assess not only the overall satisfaction with their work, but also to evaluate its components. The methodology includes a questionnaire of 18 questions, each of which offers 3 options for an answer.

Satisfaction with life was measured by the "Satisfaction Scale with Life Scale" (SWLS) for short, - a short screening self-questionnaire designed for mass surveys of respondents about the degree of subjective satisfaction with their lives. Suggested E. Diener, R.A. Emmons, R.J. Larsen and S. Griffin in 1985, adapted in Russian and validated by Osin EN and Leontiev in 2003. ${ }^{26}$ The subject is offered five statements with which he can fully or partially agree or disagree. For this, a 7-point scale is used - from "completely disagree" to "completely agree". Used a test questionnaire V.V. Stolin satisfaction with marriage, ${ }^{3}$ designed for express diagnosis of the degree of satisfaction-dissatisfaction with marriage. The questionnaire is a one-dimensional scale consisting of 24 statements pertaining to various areas: the perception of oneself and the partner, the opinion, evaluation, installation, etc. To each statement there correspond three variants of the answer: "true; Hard to say; wrong". This technique not only states the picture of existing marital relations, but also provides an opportunity for understanding the subjective world, which is being studied in all its complexity. When developing the questionnaire, the authors proceeded from the thesis that the main factor that binds conjugal unions are emotional bonds - love, emotional attachment. Accordingly, they suggested that "subjective satisfaction / dissatisfaction with marriage is by nature more a generalized emotion, a generalized experience, rather than a consequence of a rational evaluation of the success of a marriage in terms of various parameters". ${ }^{3}$ Statistical processing of test results was carried out using the SPSS package, version 18.00. The following programs were used: calculation of Pearson correlations, verification of the reliability of differences in the mean values of the variables studied with the help of the t-test for independent samples, checking the degree of compliance of samples with the normal distribution law. In this study, a bilateral significance level of $\mathrm{p}=.05$ was adopted.

\section{Results}

In Tables $1-3$ presents the results for:

1. A combined group of 193 women.

2. Samples only from married women $(\mathrm{N}=122)$ and unmarried women $(\mathrm{N}=71)$.

3. A combined group of 228 men.

4. A sample representing 160 married men.

Notation in Table 2: "X" - correlation was not calculated. Presented in Table 2 correlations of assertiveness with social selfcontrol, satisfaction with work and life in general were statistically significant only for women and insignificant for men, and therefore are not reflected in this table. The relationship of assertiveness with the satisfaction of marriage takes place in men, but is not significant in women. At the same time, satisfaction with marriage is not related to the length of family service, both in men and women. For married men and for married women, there is a positive, highly significant correlation between satisfaction with marriage and life in general $(\mathrm{R}=.429, \mathrm{p}<.001$ for men and $\mathrm{R}=.517, \mathrm{p}<.001$ for women, respectively). For women, satisfaction with work is positively related to satisfaction with life in general $(\mathrm{R}=.196, \mathrm{p}=.008)$ and negatively - with social self-control $(\mathrm{R}=-.150, \mathrm{p}=.042)$. In all the tested groups, there are negative correlations between the indices of all five strategies of behavior in the conflict. For example, in Table 3, we give the corresponding results for correlations of the rivalry indicators. The choice as an example of this strategy is motivated by the fact that it is precisely the relationship of assertiveness with the strategy of rivalry that takes place for men and women, both in this work and in foreign studies (Table 3). ${ }^{6,18,27}$

In the strategies of behavior in conflict common for men and women is:

1. A positive relationship of assertiveness with such a strategy of behavior in the conflict as a rivalry.

2. A negative relationship with the adaptation strategy.

3. A lack of connection with the strategy of cooperation. 
Table I Correlations of assertiveness with strategies of behavior in conflict $(\mathrm{N}=774)$

\begin{tabular}{lllllllll}
\hline & \multicolumn{1}{l}{ Rivalry } & & \multicolumn{2}{c}{ Compromise } & \multicolumn{2}{c}{ Device } & \multicolumn{2}{c}{ shunning } \\
\cline { 2 - 8 } & $\mathbf{R}$ & $\mathbf{P}$ & $\mathbf{R}$ & $\mathbf{P}$ & $\mathbf{R}$ & $\mathbf{P}$ & $\mathbf{R}$ & $\mathbf{P}$ \\
\hline Women $(\mathrm{N}=193)$ & 0.176 & 0.03 & 0.172 & 0.02 & -0.262 & $<.001$ & - & - \\
Men $(\mathrm{N}=228)$ & 0.178 & 0.009 & - & - & -0.158 & 0.02 & -0.159 & 0.019 \\
\hline
\end{tabular}

The symbols in Table I-3: $R$ - Pearson's correlation coefficient, $p$ - sided significance; «-» means no correlations statistically significant at $p=.05$.

Table 2 Correlations of the indicator of women's assertiveness with social self-control, satisfaction with work and life in general ( $\mathrm{N}=386$ )'

\begin{tabular}{|c|c|c|c|c|c|c|c|c|}
\hline & \multicolumn{2}{|c|}{ Satisfied Nost difficulty } & \multicolumn{2}{|c|}{ Satisfaction with Nost life } & \multicolumn{2}{|c|}{ Satisfaction with Nost marriage } & \multicolumn{2}{|c|}{ Social self control } \\
\hline & $\mathbf{R}$ & $\mathbf{p}$ & $\mathbf{R}$ & $\mathbf{p}$ & $\mathbf{R}$ & $\mathbf{p}$ & $\mathbf{R}$ & $\mathbf{p}$ \\
\hline Women $(\mathrm{N}=193)$ & 0.173 & 0.019 & 0.251 & 0.001 & $\mathrm{X}$ & $\mathrm{x}$ & 0.22 & 0.003 \\
\hline Married $(\mathrm{N}=122)$ & 0.225 & 0.013 & 0.256 & 0.004 & & & & \\
\hline Unmarried $(\mathrm{N}=7 \mathrm{I})$ & & & 0.26 & 0.017 & $x$ & $x$ & 0.308 & 0.004 \\
\hline
\end{tabular}

The symbols in Table 2"X"- correlation is calculated.

Table 3 Correlation of the strategy of competition with other strategies of behavior in the conflict ( $\mathrm{N}=774)$. Thus, in social interactions assertive men and women have something in common and at the same time there are many differences

\begin{tabular}{lllllllll}
\hline & Device & \multicolumn{2}{c}{ shunning } & \multicolumn{2}{c}{ Compromise } & \multicolumn{2}{c}{ Cooperation } \\
\cline { 2 - 9 } & $\mathbf{R}$ & $\mathbf{P}$ & $\mathbf{R}$ & $\mathbf{P}$ & $\mathbf{R}$ & $\mathbf{P}$ & $\mathbf{R}$ & $\mathbf{P}$ \\
\hline Women $(\mathrm{N}=193)$ & -0.507 & 0 & -0.402 & 0 & -0.161 & 0.029 & -0.132 & 0.044 \\
Married (N=122) & -0.438 & 0 & -0.378 & 0 & -0.167 & 0.046 & -0.187 & 0.033 \\
Men (N=228) & -0.44 & 0 & -0.166 & 0.014 & -0.317 & 0 & -0.171 & 0.011 \\
Unmarried $(\mathrm{N}=160)$ & -0.339 & 0 & -0.155 & 0.033 & -0.321 & 0 & -0.155 & 0.033 \\
\hline
\end{tabular}

However, there are many more differences. The first difference is that men have a negative relationship of assertiveness with tactics of avoiding conflict, which women do not have, and women have a positive relationship of assertiveness with a search for a compromise that men do not have. Differences in the part of assertiveness with communicative self-control are found out: in women this relationship is positive, and in men it is absent. The fact that in married women the relationship of assertiveness with social self-control is statistically insignificant is probably due to the fact that an assertive married woman may not be so concerned about the impression produced as a woman is unmarried. Men have a positive correlation of assertiveness with satisfaction in marriage, but there is no connection with satisfaction with work and life in general. In women, assertiveness is positively correlated with satisfaction with work and life in general, but there is no relationship of assertiveness with satisfaction in marriage. A comparison of the mean values of the studied variables in males and females, produced using the t-test for independent samples, yielded the following results. The average index of the choice of the competitive strategy for men (equal to 3.53) is statistically significant $(\mathrm{p}=.001)$, which is higher than that of women (2.33), while the average "female" indicators of the choice of cooperation strategy (7.31) and adaptation (5.29) are statistically significant $(\mathrm{p}=.005$ and $\mathrm{p}=.016)$ outnumber these figures ( 6.70 and 4.59$)$ in men. It should be noted that the revealed preference for men of the strategy of rivalry, and women of strategies of cooperation and adaptation corresponds to the established social stereotypes. The average value of "masculine" (74.38) indicators of assertiveness is statistically significantly higher than the average value of "female" (70.59), which corresponds to the earlier established ${ }^{3-19}$ results on a similar ratio of average assertiveness values.
With the accepted significance level $\mathrm{p}=.05$, the average values of "male" and "female" social self-control indicators (4.62 and 4.70), the choice of avoidance strategies (7.10 and 7.42) and compromise (7.00 and 7.14) are statistically indistinguishable; the corresponding indices of the t-test are as follows: $p=.996, p=.777, p=.237$. Satisfaction with men's life (23.65) is statistically significant $(\mathrm{p}=.05)$, which exceeds the satisfaction of women's life (22.08). Satisfaction with the work of women (18.38) exceeds that of men (17.67), but with the accepted significance level of $\mathrm{p}=.05$, these discrepancies are statistically indistinguishable $(p=.096)$. Satisfaction with the marriage of men (self-esteem in different groups from 32.64 to 34.02 ) is statistically significant $(\mathrm{p}=.008)$ superior to the satisfaction with the marriage of women (30.85). To the indicators of men was close (34.09) satisfaction with the marriage of psychologists. Satisfaction with the life and marriage of men statistically significantly exceeds those in women. Greater satisfaction with marriage of men compared with women is confirmed by other studies. The discussion of the results comparison with the results of foreign research. The conclusion of this study that in the Russian-speaking community in strategies of behavior in the conflict common to men and women is the positive relationship of assertiveness with the choice of such strategy of behavior in the conflict, as rivalry and lack of connection with the strategy of cooperation, coincides with a similar conclusion of foreign researchers. ${ }^{6}$ Attention is drawn to the fact that the correlation coefficients we have obtained between assertiveness and women's satisfaction with life as a whole practically coincide with the correlation established in the study of John Launsbury. ${ }^{28}$ However, the results of his study did not reveal significant differences in life satisfaction in relation to sex, in contrast to the significant difference between men and women established in this study. 
At the same time, the negative relationship between the assertiveness of men and women with the adaptation strategy, as well as the negative connection with avoidance and the positive connection in women with compromise, found by us are different from the conclusion of foreign colleagues about the absence of such connections with assertiveness. The results obtained in the present study on the positive relationship between the assertiveness of women with social self-control and the absence of such a connection in men cannot be compared with other studies of this issue in view of the fact that they were not found. The opinion of foreign researchers $28,8,13,15$ about the positive relationship between levels of assertiveness and job satisfaction was found in us only for women, but not for men. The revealed absence in our men of the relationship of assertiveness with satisfaction with life also diverges from the conclusion of foreign psychologists ${ }^{9,15}$ who assert that assertiveness positively and statistically highly correlates with the satisfaction of the life of both men and women. The positive correlation of assertiveness with satisfaction of marriage in men established in the work is similar to that of foreign researchers, ${ }^{11,13}$ but the lack of relationship of assertiveness with the satisfaction of marriage in our women differs from the conclusions received abroad. The reliability of the obtained results is ensured by the representativeness of the samples used for the conclusions, the reliability and validity of the applied techniques and statistical methods, as well as the numerous logically explicable mutually consistent correlations of the variables. Let us dwell on each of these moments. The representativeness of the samples in this study is ensured by the inclusion of a sufficient number (421) of the subjects of the Russian-speaking men and women aged 22 to 77 , married and single, living in different regions and representing a wide range of ages, occupations, specializations and positions.

The number of subjects is sufficient to ensure that the identified links are statistically significant. At all stages of the study, the results of testing groups of subjects were checked for compliance with the distribution law through a singlesample Kolmogorov-Smirnov test. The computation of the statistics Z and the error probability $\mathrm{p}$ associated with it with the help of the SPSS 18.00 software package showed that the obtained distributions of the test results of all the studied variables obey the normal law. It is these samples that were used to formulate the conclusions in this paper. For example, the test scores A26 (an assessment of the degree of assertiveness) for women $(\mathrm{N}=193)$ gave the following statistic values: $\mathrm{Z}=.790$, two-sided statistical significance $\mathrm{p}=.561$; for men $(\mathrm{N}=228)$, respectively, $Z=.668$ and $p=.764)$. The deviation from the normal distribution is considered essential at a value of $p<.05$. Since in both cases the values obtained are $\mathrm{p}>, 05$, then the assertion about the normal distribution of the indicators of the assertiveness test is valid. Similarly, there is a normal distribution of the test results and all other studied personality traits of the subjects. The correspondence of test results to normal distribution allows us to apply parametric methods for statistical analysis, in particular, the t-criterion for comparing average values for independent samples. It is important that the normal distribution of test results serves as an additional (necessary) condition for both male and female samples to be "representative sections of the population". ${ }^{27}$ Thus, the representativeness of the analyzed samples at all stages of the study is again confirmed, in this case - statistical analysis. Representativeness, reliability and validity of measurement of the variables studied were ensured by the use of techniques, the reliability and validity of which was substantiated in the relevant papers..$^{3,23-25}$

Conclusions about the reliability of the differences in the mean values of the variables studied, obtained with the help of the t-test for independent samples, turned out to be valid even under the assumption of the equality of variances, and on the assumption of their inequality. The mutually consistent relationships obtained in the work and fully explainable results confirm the reliability of the facts revealed. Thus, the revealed preference for men of the strategy of rivalry, and women - of strategies of cooperation and adaptation correspond to established social stereotypes. The fact of higher "masculine" indicators of assertiveness in comparison with "feminine" is confirmed by the results of other studies."19 Positive, highly significant cross-correlations between satisfaction with work, life in general, and satisfaction with marriage are reliable, since these factors are in reality significantly interrelated, influencing each other. Negative correlations between strategies of behavior of subjects in conflicts are quite natural, presented, in particular, in Table. 3, since preference for one strategy reduces the likelihood of using others. Mutually consistent links and results not only confirm the reliability of the facts revealed. Moreover, "every case of such a correlation proves that we are dealing with a valid test, and with a valid expert". ${ }^{4}$ The same asserted the master of validation of DT. Campbell: "The assumed validity of both meters increases when there is agreement between them". ${ }^{28}$ For the reliability of the conclusions drawn, it is also important that the detected links are highly statistically significant (in comparison with the accepted level of significance $\mathrm{p}=.05$ ) correlations.

\section{Conclusion}

1. Statistically significant connections of the personality's assertiveness indicator with certain strategies of her behavior in the conflict, with her communicative self-control, her satisfaction with work, life in general, and marriage were revealed. However, the results obtained for men and for women are significantly different.

2. In strategies of behavior in conflict common for men and women is:

a. A positive relationship of assertiveness with such a strategy of behavior in the conflict as a rivalry.

b. A negative relationship with the adaptation strategy.

c. A lack of connection with the strategy of cooperation.

3. Communication assertiveness with strategies of behavior in the conflict, job satisfaction, life and marriage are in many ways different from those that are established in similar foreign studies.

4. The average indicator of the choice of the strategy of rivalry in men is statistically significantly higher than that of women, and the average "female" indicators of the choice of the strategy of cooperation and adaptation surpass those in men. ${ }^{29}$

\section{Acknowledgments}

None.

\section{Conflicts of interest}

Authors declare that there is no conflict of interest.

\section{References}

1. Bakker AB, Schaufeli WB, Leiter MP, et al. Work engagement: An emerging concept in occupational health psychology. Work \& Stress. 2008;22(3):187-200.

2. Gilbukh Yu Z. Actual problems of validating psychological tests. Questions of psychology. 1978;5:108-118.

3. Greben NF. Psychological tests for professionals. Minsk:Contemporary School. 2007.

4. Bishop S. Develop Your Assertiveness. Kogan Page. 2006. 
5. Lounsbury JW, Moffitt L, Gibson LW, et al. An Investigation of Personality Traits in Relation to Job and Career Satisfaction of Information Technology Professionals. Journal of Information Technology. 2016;(1):1-33.

6. Ma Z, Jaeger AM. A Comparative Study of The Influence of Assertiveness on Negotiation Outcomes in Canada and China. Cross Cultural Management: An International Journal. 2010;17(4):333-346.

7. Mitrofan L, Dumitrache SD. Interconnections between Assertiveness and Empathy in Couple Relationships. Journal of Experiential Psychotherapy. 2012;3(59):11-23.

8. Mueen B, Khurshid M, Hassan I. Relationship of Depression and Assertiveness in Normal Population and Depressed Individuals. Internet Journal of Medical Update .2006;2:10-17.

9. Rountree J. Personality Characteristics and Perceptions of Job Satisfaction among Mental Health Professionals. Walden university. 2011.

10. Ryan EB, Anas AP, Mays H. Assertiveness by Older Adults with Visual Impairment: Context Matters. Educational erotology. 2008;34:504-515.

11. Salleh A, Zuria M, Amla S. An Investigation of Assertiveness and Satisfaction with Life among Malaysian Secondary School Students. International Journal of Knowledge, Culture and Change Management. 2012;11(6):1-10.

12. Sheinov VP. Age and gender factors of assertiveness. System psychology and sociology. 2014;2(10):118-126.

13. Sheinov VP. Assertiveness, internality, affiliation and insecurity of the individual from manipulation: connections and properties. System psychology and sociology. 2015;14(2):107-113.

14. Sheinov VP. Determinants of assertive behavior. Psychological Journal. 2015;36(3):28-37.

15. Sheinov VP. Development of the assertiveness test satisfying the requirements of reliability and validity. Questions of psychology. 2014;2:107-116.

16. Tanck RH, Robbins PR. Assertiveness, locus of control and coping behaviors to diminish tension. Educational Gerontology. 2008;34:503519 .
17. Villa MB, Pereira Del Prette, Zilda Aparecida. Marital Satisfaction: The Role of Social Skills of Husbands and ives. Paidéia. 2013;23(56):379-387.

18. Weiss SE. Negotiators Effectiveness with Mixed Agenda: An Empirical Exploration of Tasks, Decisions and Performance Criteria. Group Decision and Negotiation. 2010;21(3)255-290.

19. Osin EN, Leontiev DA. Approbation of Russian-language versions of two scales of express assessment of subjective well-being.Proceedings of the III All-Russian Sociological Congress. Moscow: Institute of Sociology, Russian Academy of Sciences, Russian Society of Sociologists. 2008.

20. Stolin VV, Romanova TL, Butenko GP. A survey of satisfaction with marriage. Bulletin of Moscow University. Psychology. 1984;14(2):54-60.

21. Fetiskin NP, Kozlov VV, Manuylov GM. Socio-psychological diagnosis of personality development and small groups. Moscow: Publishing house of the Institute of Psychotherapy. 2002:470-473.

22. Ergenel A, Karapinar PB, Camgöz SMN. The effect of assertiveness on conflict handling styles. H.Ü. ktisadi ve dari Bilimler Fakültesi Dergisi. 2011;29(2):69-93.

23. Butt A, Zahid ZM. Effect of Assertiveness Skills on Job Burnout. International Letters of Social and Humanistic Sciences. $2015 ; 63: 218-224$

24. Amyaga NV. Methods for measuring personal representation in communication. Journal of practical psychologist. 1998;1:42-53.

25. Great psychological dictionary. Prime-EVROZNAK. 2004.

26. Campbell DT. Recommendations for APA tests standards regarding construct, trait, or discriminant validity. Am Psychologist. 1960;15(8):546-553.

27. Anastasi A, Urbina S. Psychological testing. St. Petersburg: Peter, 2002.

28. Lounsbury JW. Personality Characteristics of Business Majors as Defined by the Big Five and Narrow Personality Traits. Journal of Education for Business. 2009;84(4):200-205.

29. Ikiz FE. Self-perceptions about properties affecting assertiveness of trainee counselors. Social behavior and personality. 2011;39(2):199-206. 